\title{
Discussion on Aestheticization of Residents 'Daily Life in the Provincial Capital City of China
}

\author{
Wei-wei Liu \\ College of Information \& Business, Zhongyuan University of Technology, Zhengzhou Henan Province, China
}

\begin{abstract}
As a result of the accelerated pace of life, the growth of material consumption, the increasing of the cost of living, more and more people have given up Beijing, Shanghai and other big city life, came to the capital provincial city to live. The provincial capital city has provided the convenience for the residents on city environment construction, the public life of the community, plaza supermarket life etc. City residents' daily life has the aesthetic characteristics. The aesthetic feeling of the city people's daily life is conducive to the public to actively participate in the construction of city, it is conducive to make city people home beautiful and warm, enhance people's sense of happiness
\end{abstract}

Index Terms -provincial capital; aestheticization; home; square; supermarket

\section{Introduction}

Because of the accelerated pace $\mathrm{f}$ life, the material consumption's increasing, the cost of living's increasing, the traffic inconvenience, work pressure of competition, more and more people feel that the metropolis life is hard and not happy. More and more people turn there attention to the provincial capital city, they chose to live in the provincial capital city. So the aesthetic characteristics of the residents' daily life in the provincial capital city is important, the aspects of daily life providing convenience for the residents to build a happy living is important too. This article will carry out research using the aesthetic perspective, from the aspects of city residents living community, supermarket and square of city to city environment construction.

\section{The capital city}

The provincial capital city focus on regional economic development and regional culture in the process of city construction, city building more embodies the combination of the ancient and modern, the simple and lively, the peace and noise .Especially the citizen feel the life using aesthetic way of dedicating and the object of ablation, the realm of beauty and charm will flow in daily life naturally.

Home is the important part of public life in the city. Here, people feel the glory of family history, rich and warm affection and the sweet life extension .People decorate their warm house for their own interest .At home, people feel the initiation of all things in spring, the singing of birds in summer, the leaves falling in autumn, the falling snow in winter. People experience four seasons' changing to realize the hope of life.

Home is not only the public housing, but also the public and the community life. There are a lot of high-rise buildings and the old residential districts. Although these buildings slightly outdated in appearance, but there are the old lane pendants, lush green plants, cute pets, the old man teeters, lively and lovely children, deep neighborhood. There are the familiar cries, car horn sound, the school bell, flowing with the smell of bread and fruits. Because of people's life, the city has sound, color even the smell, city life is more colorful, the city residents have more aesthetic appreciation and experience. This is the gospel form provincial capital city, so more people choose to live in the. provincial capital city.

Compared with modern metropolitan city, the provincial capital city's pace of life is slightly slower, and the community life of the residents is rich and colorful .As night falls, the community center is crowded, singing and laughter can be heard without end. The dance team, choir, fans group, chess club, and other activities of various forms enrich the lives of community residents.

Starting from the home, more people's activity places are square and the supermarket. The supermarket and square are the city window to show the beauty of city environment There is a large number of leisure squares in the provincial capital city, the square has large area of floor space. There are a lot of grass, trees, fountains and fitness equipments. Square open to all citizens, not needing to pay tickets, also there is not be crowded. Children play in square, the old men walk,, young people chat with each other here, people can feel the moist air, enjoy the fragrance gladdening the heart and refreshing the mind, listen to the wind through the leaves. City Leisure Square has become the city's natural oxygen bar and entertainment field releasing pressure on life and work. In addition, some square building, the statue show the historical and cultural heritage of the square, stone, gallery frame, chair highlight the square humanistic care, people can stay, rest, watch, read, communicate. Give an example, "two seven" Square is located in Zhengzhou city of HeNan Province, landmark of "two seven" stands in the center of the square, building for commemorating the February 7, 1923 Jing Han railway workers' striking. The chairs on both sides of the square are provided for visitors to rest.There are a lot of shops surrounding the square The square has been the gathering. for citizens' shopping and leisure tourism.

There are more supermarkets in the provincial capital city and the distance is not far from people living place, people can walk to shop. Consumers walk into beautifully decorated supermarket, stroll between the shelves of goods accompanied by melodious music, select the goods they need, enjoy the convenience and efficient service provided by businesses. As a public place, the supermarket has become an important platform for urban communication. Although shoppers do not 
know each other, but shopping and walking in the supermarket may shorten the distance between strangers, experience similar lifestyles. The emotion is closely.

Although the provincial capital city is less wealth and prosperity compared with the modern metropolis, but in recent years, the function of provincial capital city environment continues to demonstrate to cater to the public aesthetic taste, providing convenience for people's life. Delicious regional diet is known for Chinese and foreigners, clothing wholesale market provide numerous options for people's dress. The residential environment area provide living guarantee for people. Convenient traffic tools enable people to travel far away from Traffic jam .

The capital city is the political and economic center in province, is also a cultural center, there is lot of cultural heritage in the development process of the history, such as the ancient architectural buildings, antiquities, ancient ruins, celebrity anecdotes, customs and so on, it is a valuable asset for citizen. Moreover, people develop, exploit and create the cultural resources constantly by the means of science and technology, so the provincial capital city will continue to highlight the unique advantages of culture. People can be immersed in a thick cultural atmosphere, Immersed in the beauty caused by the collision of modern civilization and ancient civilization. In case of Zhengzhou city of HeNan Province, Zhengzhou is a historic and cultural city, is the cradle of the Chinese nation and Chinese ancient civilization earliest. At present, the development of the historical cultural resources make people's daily life with the factors of civilization heritage. From the beginning of 2006, Zhengzhou City hold "Huang Di hometown shrine worship" activities in March each year, the Chinese all over the world come to participate in the ancestral worship activities in the hometown of Huang Di. This is conducive to the development of celebrity city historical and cultural resources, this is conducive to gather the centripetal force from all the children of the Yellow Emperor .

\section{Conclusion}

City is people's living home, is the initiation of humanity, it makes the human emotion continued. People feel strong emotion consanguinity, close, the joy of life, the meaning of existence. With the development of society and history, the progress of science and technology, city change from the market town to modern metropolis. With the changes of the city, there are many problems left: the high-rise buildings have covered the blue sky; traffic jam has caused inconvenience for people's life; city water and air pollution were caused by chemical enterprises; city crime has brought security risks for people. When more negative evaluations on city come in great numbers, only look at daily life with aesthetic vision, we can participate in everyday life totally, appreciate the beauty of life, love our city, then take practical action to change the negative factors into positive value, experience the happy memories of city ${ }^{1}$.

\section{References}

[1] Shan Qixiang. Retain the "root" and "soul" of city culture -- Exploration and practice on China cultural heritage protection. Beijiing: Science Press, 2010.

[2] Lu Caiyun, Chen Bin. The path of China's capital city cultural function and development. Hunan Social Sciences, 2013,(1): 220-223.

[3] Yao Haiming. The supermarket culture. Journal of Suzhou University, 1997,(1): 46-47.

[4] Wang Xiaoxiao. The city square in the city's role. Study on Art Education, 2010,(1): 113-114.

\footnotetext{
${ }^{1}$ Chen Libo. "Four city aesthetics". BeiJing: China Power Press, 2009: 121126.
} 